\title{
Conflicts of Interest: Bias or Boon?
}

\author{
Christian Tomaszewski, MD
}

Carolinas Medical Center, Charlotte, North Carolina

"He who would do a great evil must first of all convince himself he is doing a great good" [Mahatma Gandhi].

Most physicians have received a parking ticket, and a few have even been sued; but how many do you know have been banned from publishing in a medical journal for one entire year? Dr. Randall Wolf, a surgeon at the University of Cincinnati, now has the latter distinction [1]. The Journal of Thoracic and Cardiovascular Surgery claimed that Dr. Wolf failed to fully disclose his financial association with AtriCure, a company that markets a system for treating atrial fibrillation. His study, not surprisingly, showed results favorable for the system. Dr. Wolf claimed he disclosed all his conflicts of interest, including an educational grant from AtriCure. However, he failed to mention that he owned 18,402 shares, with warrants and options to purchase 13,913 additional shares, of AtriCure stock [2]. So in the end, an oversight of an obvious conflict of interest was discovered and resulted in sanctions for the individual involved.

Why should we care if Dr. Wolf had a few shares of a company whose products he was researching? Good science is good science, regardless of funding. But this may not always be the case when there is a conflict of interest-a set of conditions in which the professional judgment concerning a primary interest tends to be unduly influenced by a secondary interest. In other words, the welfare of patients and validity of research may be undermined by potential financial gain. Dr. Wolf's glaring error is not his potential gain in stock appreciation, but the potential bias in his study results and interpretation. Ultimately, this impacts the integrity of science. It is too easy to lose public confidence, especially when exaggerated headlines state that "Study Finds That Medical Research is Often Wrong" [3]. This nugget of partial truth stems form a recent JAMA study showing that nearly one-third of large randomized clinical trials published from 1990 to 2003 had either exaggerated results or results that were later contradicted [4]. The most notorious example was the erroneous touted ability of hormone therapy to reduce coronary artery disease in women. Why does this happen? Partly, the JAMA study indicated, this is due to the use of surrogate markers and publication bias, both often associated with sponsored studies.

The pharmaceutical industry has tremendous financial influence. In 2004, the FDA approved 380 generics and 113 new drug applications [5]. Current expenditures to bring a new drug to market, \$138 million in 1975, are now exceeding \$800 million as of 2001 [6]. Much of this money goes to fund clinical research, over $\$ 40$ billion alone in 2004 among members of the Pharmaceutical Researcher and Manufacturers of America (PhRMA), 15\% of the total pharmaceutical budget [7]. But this pales in comparison to the $31 \%$ ( $\$ 67$ billion) spent on marketing and administration. All this largesse translates into, as of 2001, 80,000 clinical trials going on in the U.S., with 2.3 million Americans having served as subjects [8]. Up to one quarter of academic investigators in biomedical research receive industry funding [9]. Accompanying this alarming statistic is that almost half of investigators received research related gifts, items definitely not integral to the research process. Because research requires financial support, conflicts of interest are now inherent in the scientific process.

Just as in accepting campaign contributions, taking pharmaceutical money in itself does not necessarily buy one a ticket on the proverbial "handbasket to hell." But unless one is careful, influence can certainly bias research. Countless studies have shown that even when correcting for other confounders, industry funding is probably one of the best predictors for a result favorable toward the product being studied [10-14]. In other words, trials that report industry funding are almost twice as likely (adjusted OR 1.8 with 95\% C.I. 1.1-3.0) to have a statistically significant pro-industry result [15]. Another study showed that funding by for profit companies resulted in a 51\% favorable recommendation for the studied, experimental drug, versus only $16 \%$ if funded by non-profits-as based on a review of 170

Keywords: conflicts of interest, research funding, research bias

Notes: There was no funding for this editorial.

Corresponding Author: Christian Tomaszewski, MD, Dept of Emerg Med, Carolinas Medical Center, Charlotte, NC 28203. 704-355-7210. Email: ctomaszewski@carolinas.org 
randomized clinical trails in 2001 [16]. And finally, a recent meta-analysis of eight articles, that together compiled a total of 1140 studies, showed a robust 3.6 odds ratio (95\% C.I. 2.6-4.9) favoring pro-industry conclusions when sponsorship was from industry [9]. All this overwhelming data suggests that industry funding definitely creates a powerful, potential bias within the methodology of any clinical research trial.

In the defense of industry trials, there are reasons other than unethical influence that guarantee favorable industry trials for studied drugs. Pharmaceutical manufacturers are not going to violate the uncertainty principle; they are going to support proven winners with potential. But below the surface we need to be wary of undue influence on the final results of a study. Pharmaceutical firms have been accused of unfairly stacking studies, partly by restricting publication and data sharing [9]. For example, in May 1999, as lead investigator, Dr. James Kahn halted a study involving over 2500 patients and 77 hospitals because the study drug, Remune (an immunologic modifier) failed to halt the progress of HIV disease [17]. The manufacturer, Immune Response, refused to release subsequent data from affiliate hospitals and tried to block publication of the disparaging results [18]. Defiantly, Dr. Kahn published, prompting a lawsuit in September of 2000 seeking $\$ 7$ million in damages from UCSF, Dr. Kahn's institution. After excessive pressure from the academic community, Immune Response dropped the lawsuit and the additional data was released. (For your personal information, Immune Response's stock prices crashed, going from a high of over \$35 in 2000 to- literally_a dime a share. Immune Response now faces lawsuits from disgruntled investors). In a capitalist system, good science eventually prevails and unethical behavior is appropriately punished.

Other companies have also withheld critical research data, only to be burned later. There is the famous case of the unfortunate Dr. Betty Dong, a pharmaceutical researcher, whose industry sponsored study showed equivalency of generics preparations in comparison to Synthroid, the sponsor of the study [19]. Although she completed the study in 1990, the manufacturer of Synthroid managed to block publication for seven years until the FDA finally intervened [20]. Again justice prevailed, and in August of 2000, former Synthroid users favorably settled a class action lawsuit to the tune of \$91 million [21].

Marketing "studies" published as original research present an even bigger problem with industry sponsored trials where disclosure might help. In 2003, Parke Davis turned a novel drug (Gabapentin (Neurontin) approved in 1994 specifically and only for the shingles pain and select seizure disorders) into a major $\$ 2.7$ billion blockbuster. How did they do this without changing the indication labeling? In 1994, 80\% of the prescriptions were for unapproved uses, including tension headaches and restless leg syndrome. Their success was partly attributable to a clever publication strategy, where the company sponsored minimal research, often with placebo comparisons and inactive controls. Parke Davis paid as much as $\$ 12,000$ per article to medical education and communication companies to prepare articles [22]. In addition, academic researchers were recruited to "author" these articles at \$1000 a pop, knowing: "draft complete, we just need an author" [23]. In spite of the lack of full disclosure and unprincipled shenanigans, justice prevailed again. On 13 May 2004, Parke Davis agreed to pay $\$ 430$ million in fines and civil damages for engaging in the illegal activities associated with the promotion of Neurontin for unapproved uses [24]. Regulatory authorities do not take kindly to the promotion of marketing inducements as research and have fined many other pharmaceutical firms for comparable amounts as those levied against Parke Davis.

But disclosure is not enough, if we cannot get authors to comply. Since 1984, the New England Journal of Medicine (NEJM) requires full disclosure among authors. In spite of this, a recent study of four major leading journals, including NEJM, showed lack of enforcement. Out of 163 articles published between December 2003 and February 2004, authors of 13 (8\%) articles failed to report relevant conflicts of interests to readers [25]. Authors of another 11 articles failed to report unrelated conflicts of interest. Other journals have the same problems. Randomized clinical oncology trials from 12 international journals published between 1999 and 2003 showed that only 41 (18\%) of the industry sponsored studies reported the role of the sponsor [26]. And as most would agree, it is difficult to catch scientists who cheat, especially if it is in select areas of science such as toxicology [27].

So if we want disclosure, how do we encourage authors to comply? Publication bans, such as the one used by the Journal of Thoracic and Cardiovascular Research, involve prohibitive policing, not to mention dealing with possible appeals. And, realistically, how many authors of manuscripts in the Journal of Medical Toxicology (JMT) will feel threatened by such a penalty? Another method is public humiliation. A recent astute letter to the editor called a previous author to task for publishing a cardiology update without mentioning his obvious ties to the manufacturer of atorvastatin [28]. The toxicological community remains a close-knit group, and the most likely person to pick up on a disclosure violation would be a colleague, as is the case for most research fraud.

Another method to prevent lapses in disclosure of conflicts is a tight review process. This has worked in a case where duplication of published data and obvious ghost writing was revealed. Editors believed that a pharmaceutical representative probably wrote the article because the style completely differed from the typical style employed by the alleged senior author. When the "author" was confronted, the manuscript was withdrawn without admission of guilt [29].

Must of this discussion addressed original studies, particularly randomized clinical trials, which have the greatest potential influence on our practice. But another area with as much, or even more, influence, are reviews and editorials. Major journals, like The New England Journal of Medicine and The Lancet, exclude authors who have conflicts of interest related to such manuscripts [30,31]. On the surface this seems like an admirable policy, but other journals have found the potential to stymie critical discourse [32]. The Annals of Internal Medicine recently received 
an unsolicited critique from an author with direct conflicts of interest. In spite of the editorial nature of the submission, the journal published the manuscript, along with a rebuttal, in the interest of scientific discord. Authors with no interest or conflict regarding the products discussed write some of the most balanced review articles, but one must keep in mind that our most knowledgeable authors may be those intimately involved with such products. Still, it is in the best interests of the Journal of Medical Toxicology that we not actively seek reviews and editorials from those with obvious conflicts of interest. However, if received, reviews and editorials with direct author conflicts will not be automatically rejected without first undergoing careful editorial and reviewer consideration. To exclude certain works because of conflict of interest could amount to unfair censorship, and possibly result in the loss of valuable discourse.

Because a conflict of interest exists, it does not mean that a manuscript should be discarded. The responsibility remains with the authors who must disclose the extent of such relationships, while assuring the scientific community that they had full access to all data and are responsible for the integrity of their analysis. As mentioned earlier, financial support from interested parties remains a very real scientific confounder that may bias the results of any study. Therefore, in accordance with the International Committee of Medical Journal Editors, all JMT authors must disclose all financial relationships that might bias their submission [33]. Although articles will be blinded, such conflicts will be disclosed ahead of time to reviewers to heighten their vigilance. Editors and reviewers at the JMT must also disclose conflicts of interest, especially if it could bias their opinion of a manuscript under review. Even with such "honor code" safeguards, failure of conflict disclosure may occur. If at any time a reader brings a credible lapse to our attention, it will be published as a letter to the editor with a rebuttal solicited from the questioned author. Every author has some potential gain from publication, and occasionally it may not be in the best interests of the toxicological community. To paraphrase Ghandi, "to do a great evil, one must first convince the [scientific community] that one is doing a great good." Hopefully, our current process will remove and stop the rare individual who inadvertently attempts to do a "great evil" thereby threatening the credibility of our new flagship, ACMT scientific publication, the Journal of Medical Toxicology.

The author has no potential financial conflicts of interest to report.

\section{REFERENCES}

1. Mayor S. Surgery journal bans authors who hide conflicts of interest. BMJ 2006; 332:135.

2. Armstrong D. Surgery journal threatens ban for authors' hidden conflicts. Wall Street Journal 28 Dec 2005; B1.

3. Study Finds That Medical Research is Often Wrong. Associated Press. 14 July 2005. Available from: www.foxnews.com/ story/0,2933,162441,00.html
4. Ioannidis JP. Contradicted and initially stronger effects in highly cited clinical research. JAMA 2005; 294(2):218-228.

5. FDA. New and generic drug approvals. Drugs@FDA Data Files. 22 Feb 2006. Available from: http://www.fda.gov/cder/ drugsatfda/datafiles/default.htm.

6. DiMasi JA, Hansen RW, Grabowski HG. The price of innovation: new estimates of drug development costs. J Health Economics 2003; 22:151-185.

7. PhRMA Annual Report 2005-2006. 1-32. 2006. Available from: www.phrma.org/files/AnnualReport20052006.pdf

8. Aoki N. Trials and errors. Boston Globe. 12 June 2002.

9. Bekelman J, Li Y, Gross C. Scope and impact of financial conflicts of interest in biomedical research. JAMA 2003;

289:454-465.

10. Perlis RH, Perlis CS, Wu Y, Hwang C, Joseph M, Nierenberg AA. Industry sponsorship and financial conflict of interest in the reporting of clinical trials in psychiatry. American Journal of Psychiatry 2005; 162:1957-60.

11. Kjaergard LL, Als-Nielsen B. Association between competing interests and authors' conclusions: epidemiological study of randomised clinical trials published in the BMJ. BMJ 2002; 325:429.

12. Djulbegovic B, Lacevic M, Cantor A, Fields KK, Bennett $\mathrm{CL}$, Adams JR et al. The uncertainty principle and industrysponsored research. Lancet 2000; 356:635-638.

13. Friedberg M, Saffran B, Stinson TJ, Nelson W, Bennett CL. Evaluation of conflict of interest in economic analyses of new drugs used in oncology. JAMA 1999; 282:1453-1457.

14. Stelfox HT, Chua G, O'Rourke K, Detsky AS. Confict of interest in the debate over calcium-channel antagonists. N Engl J Med 1998; 338:101-106.

15. Bhandari M, Busse JW, Jackowski D, Montori VM, Schunemann $\mathrm{H}$, Sprague $\mathrm{S}$ et al. Association between industry funding and statistically significant pro-industry findings in medical and surgical randomized trials. [see comment]. CMAJ Canadian Medical Association Journal 2004; 170(4):477-80.

16. Als-Nielsen B, Chen W, Gluud C, Kjaergard LL. Association of funding and conclusions in randomized drug trials: A reflection of treatment effect of adverse events? JAMA 2003; 290:921-928.

17. Gottlieb S. Firm tried to block report on failure of AIDS vaccine. BMJ 2000; 321:1173.

18. Kahn JO, Cherng DW, Mayer K, Murray H, Lagakos S. Evaluation of HIV-1 Immunogen, an immunologic modifier, administered to patients infected with HIV having 300 to $549 \times 10^{6}$ /L CD4 cell counts: A randomized controlled trial. JAMA 2000; 284:2193-2202.

19. Rennie D. Thyroid storm. JAMA 1997; 277:1238-1243.

20. Dong B, Hauck WW, Gambertoglio JG, Gee L, White JR, Bubp JL et al. Bioequivalence of generic and brand-name levothyroxine products in the treatment of hypothyroidism. JAMA 1997; 277:1205-1213.

21. U.S.District Court. Synthroid Marketing Litigation. 97 C 6017. 2000. Northern District of Illinois, Eastern Division. 1 Nov 1999. www.synthroidclaims.com/notice.pdf. 
22. Kowalczyk L. Use of drug soars despite controversy. Boston Globe 25 Nov 2002; A1.

23. Kowalczyk L. Drug company push on doctors disclosed. Boston Globe 19 May 2002; A1.

24. Harris G. Pfizer to pay $\$ 430$ million over promoting drug to doctors. New York Times 14 May 2004; C1.

25. Goozner M. Unrevealed: Non-disclosure of conflicts of interest in four leading medical and scientific journals. 1-16. 12 July 2004. Washington, D.C., Center for Science in the Public Interest.

26. Tuech JJ, Moutel G, Pessaux P, Thoma V, Schraub S, Herve C. Disclosure of competing financial interests and role of sponsors in phase III cancer trials. European Journal of Cancer 2005; 41:2237-40

27. Weiss R. Deception by scientists relatively rare. Washington Post 15 Jan 2006; A19.
28. Musher DM, Stone PH. Undisclosed Conflicts of Interest. Annals of Internal Medicine 2006; 144:225.

29. Bevan JC. Ethical behaviour of authors in biomedical journalism. Annals of the Royal College of Physicians and Surgeons of Canada 2002; 35:81-85.

30. Drazen JM, Curfman GD. Financial associations of authors. N Engl J Med 2002; 346:1901-1902.

31. James A, Horton R, Collingridge D, McConnell J, Butcher J. The Lancet's policy on conflicts of interest. Lancet 2004; 363:2-3.

32. Publishing commentary by authors with potential conflicts of interest: when, why, and how.[comment]. Annals of Internal Medicine 2004; 141:73-4.

33. International Committee of Medical Journal Editors. Uniform requirements for mansucripts submitted to biomedical journals: Writing and editing for biomedical publication. 1-35. 2006. www.icmje.org. 